\title{
Stress, frustration, boredom, and fatigue in online engineering education during the pandemic
}

\author{
Valentina Iuliana Manea ${ }^{1}$, Tudor Macavei ${ }^{1}$, Costin Pribeanu ${ }^{2}$ \\ ${ }^{1}$ Technical University of Civil Engineering, \\ Bucharest, Romania \\ E-mail:valentina.manea@utcb.ro,tudor.macavei@utcb.ro \\ ${ }^{2}$ Academy of Romanian Scientists \\ 3 Ilfov street, 5091859, Bucharest, Romania \\ E-mail: costin.pribeanu@gmail.com
}

\begin{abstract}
The educational crisis process generated by the Coronavirus COVID-19 had major consequences on the academic and personal life of university students. Universities had to move from the traditional classes and laboratories to the online platform. As extant research shows, this shift to online education had many negative consequences. The objective of this research is to analyze in more detail the relationship between stress, frustration, boredom, and fatigue and to identify the main factors that affect the online learning experience of students during the pandemic. The analysis is a mix of a quantitative and qualitative study that has been done on a sample of 177 university students from a university of construction engineering in Bucharest. The analysis of quantitative data revealed a significant and relatively high correlation between stress, frustration, boredom, and fatigue. The qualitative analysis sheds light on the relationship between these variables and the loss of attention, learning difficulties, and lack of face-to-face communication, socialization, and interaction.
\end{abstract}

Keywords: online lectures, frustration, stress, boredom, pandemic, engineering education.

DOI: $10.37789 /$ ijusi.2020.13.4.2

\section{Introduction}

The unexpected crisis provoked by the pandemic forced universities to go online, thus affecting teachers' and students' university and personal lives. The shift from traditional to online education in the coronavirus COVID-19 context had many disadvantages. As many studies show, university students complained about the lack of socialization, lack of interaction with the teacher, increased workload, distraction, frustration, stress, and technical issues (Aristovnik et al., 2020; Chakraborty et al., 2020; Faize \& Nawaz, 2020; Lamanauskas \& Makaraskaite-Petkevitciene, 2021; Gorghiu et al., 
2021).

The analysis of disadvantages of distance education during the pandemic is difficult since home confinement changed radically the life of people. For university students, it changed the places: the university spaces where they attend lectures, carry on laboratory works, interact with teachers and colleagues became inaccessible. Instead, the home which previously has been a place for personal life and individual study has been invaded by academic activities.

Several recent studies that are investigating the drawbacks of an exclusive online education found that stress is a serious issue that negatively affects academic performance (Debowska et al., 2020; Lautenbach and Randell, 2021; Gaikwad \& Kulkarni; 2021). In a recent study (Gorghiu et al., 2021), the frustration and stress experienced by university students from Romania and Lithuania have been analyzed. The study took a regression analysis approach and revealed that concentration issues, learning difficulties, boredom, and fatigue have a significant positive influence on the frustration experienced by students.

The objective of this research is to analyze in more detail the relationship between stress, frustration, boredom, and fatigue and to identify the main factors that affect the online education experience during the pandemic generated by the Coronavirus COVID-19. This exploratory study is a mix of quantitative and qualitative analysis: correlation analysis, regression analysis, and analysis of university students' opinions as regards the disadvantages of online education at a construction engineering university in Bucharest.

The rest of this paper is structured as follows. Related work is discussed in the next section. The method and sample are presented in section 3. Section 4 presents and discusses the results of the study. The paper ends with a conclusion in section 5 .

\section{Related work}

Zurlo et al. (2020) developed a Covid-19 students stress questionnaire. The questionnaire (CSSC) has 7 items that refer to relationships and academic life, isolation, and fear of contagion. They validated the questionnaire on a sample of 514 university students from Italy and found that the highest mean values of stress are associated with relationships and academic life.

The study of Debowska et al. (2020) analyzed the students' stress, anxiety, 
and depression on a sample of 7228 Polish university students. They collected data in 5 stages, during the first two months and found that female students experienced higher levels of anxiety, depression, and stress.

Chakraborty et al. (2020) analyzed the opinions of 358 students from an Indian university of technology. They found that about $66 \%$ of them are stressed about losing Internet connection and about $75 \%$ are complaining of excessive screen time causing stress and sleep difficulties.

The study of Moawad (2020) targeted the academic stress experienced by university students in online learning during the pandemic. The study analyzed 6 stressor themes (fear and concerns): exams, assignments, lecture time, home setting, internet, and uncertainty. The internet issues have been mentioned by $17 \%$ of the male students and $11 \%$ of the female students.

Aristovnik et al. (2020) conducted a large-scale survey collecting opinions from 30383 students from 62 countries. More than $42 \%$ of students reported that their workload during online classes was higher. As regards the negative emotions, the most frequently mentioned were boredom (45\%), anxiety $(40 \%)$, and frustration (39\%). About half of the students complained of not having a quiet place for study and about one-third of them don't have regular access to a printer.

Mark et al. (2008) analyzed the cost of interrupted work and found that people can compensate for interruptions by working faster. The cost of this adaptation is more stress and effort, higher frustration, and higher time pressure.

Aguilera-Hermida (2020) analyzed the acceptance of emergency online learning during the pandemic based on quantitative and qualitative data from 270 college students. Students reported concentration difficulties while being home, difficulties related to balance school-related and family activities, feeling tired because of prolonged exposer to the screen, lack of communication with teachers, technical issues, stress due to increased workload, decrease in the quality of the learning process, and decrease in the motivation to learn.

Mhedly et al. (2020) analyzed the influence of prolonged exposure to digital devices during the pandemic on stress, exhaustion, and burnout. Their study resulted in a set of coping strategies for reducing the level of stress during online sessions. The strategies are advocating for raising awareness on stress and burnout related to increased use of digital devices, getting feedback from students as regards their feelings, and conducting surveys to test the 
level of stress. The authors also recommended increasing the frequency of breaks between online classes to reduce exposure time and prevent loss of attention.

Rahiem (2020) studied how the Covid-19 crisis impacted the remote learning experience of university students in Indonesia. He found that the learning experience was paradoxical in that students perceived it as having both positive and negative aspects. Learning from home has been found as quiet and comfortable but also noisy and disturbing. Time management has been found as both flexible (breaks and rest during learning) and stressful (overload assignments, tiring).

The study of Wang et al. (2021) analyzed the role of students' digital competence in preserving psychological well-being during the pandemic through the lens of self-determination theory (Deci \& Ryan, 2008). The study tested a structural model with three constructs conceptualizing the selfdetermined motivation (help-seeking, digital competence, and learning agency) that are influencing academic burnout and learning engagement. The influence is mediated by two constructs: mental load and mental effort. They found a positive correlation between mental effort and academic burnout which, in turn, affected student learning engagement. Digital competence had the highest influence on students' engagement in online learning.

Hagedorn et al. (2021) analyzed academic and psychological frustration during the pandemic on a sample of 2643 university students. They identified eight kinds of frustration, out of which four are academic frustrations and four are psychological frustrations. The academic frustrations are related to technology (connection and equipment), classwork (format, quality, schedule, workload, professor and university communication), research (lab and equipment), and family. Psychosocial frustrations are related to social aspects (work/life balance, isolation), emotional issues (stress, mental health), behavioral (sleep, screen time), and financial. The period during the pandemic has been described by some students as the most stressful time since being a student.

A recent study by Lamanauskas and Makaraskaite-Petkevitciene (2021), analyzed the advantages and disadvantages of distance learning. They found that distance learning has several disadvantages: negative effects on mental health (19\%), lack of socialization (15\%), limitation of practical activities (14\%), lower level of engagement (12\%), lack of communication $(10 \%)$, negative effects on the physical health ( $9 \%)$, and increased learning load 
(5\%). The most important shortcomings of distance lectures have been grouped into two categories that account for more than a half of students' opinions: physical and mental health deterioration $(27.7 \%)$ and nonrealization of social needs $(24.7 \%)$.

Day et al. (2021) analyzed the immediate impact of the pandemic on the postsecondary teaching and larning geography based on data from six institutions from three countries. They analyzed in more detail the opinion of undergraduate students that had both live and remote lectures. They found that students from three classes liked working at home and looking at recorded lectures but reported that working home, communicating with professors, and doing labs in isolation is hard. Students also complained about the lack of motivation, missing the learning community, and missing social aspects in class. Other issues, mentioned in one or two classes were related to poor internet access, eye strain due to looking at screen all time, working in groups, and inadequate devices. The authors noticed that for students that were familiar with online learning it was easier to shift to distance learning.

Asgari et al. (2021) highlighted the fact that hands-on training is an important component of engineering education and the lack of true laboratory works will have a negative impact on students' formation. They surveyed 627 university students from different engineering departments and found that $70 \%$ experienced Zoom fatigue or difficulties in maintaining their focus. Most of the students reported a lack of engagement (64\%) and social disconnection $(55 \%)$. Other complaints as regards the online instruction were related to work-life balance issues (30\%) and lack of motivation (55\%).

In a similar vein, Johnson \& Barr (2021) stressed the importance of handson experience for engineering education as a basis for a sound foundation for the application of theoretical concepts in practice. They found that the lack of this kind of experience has several negative effects: difficulties in learning and remembering details, lack of engagement, and educational loss. Their results also highlighted the loss of a social learning environment where students interact with each other and may receive guidance in real-time. 


\section{Method and sample}

\subsection{Sample}

A questionnaire has been administrated to students from the Technical University of Building Engineering in Bucharest that includes statements to be evaluated on a 5-points Likert scale, and open-ended questions. This study is focusing on six items and one open-ended question that refer to the perceived disadvantages of online classes.

A number of 217 students answered the questionnaire. However, a number of 40 of them didn't mention any disadvantage, thus resulting in a working sample of 177 observations (108 male students / 69 female students), most of them undergraduates. Students are enrolled in different study programs: civil engineering, railways, roads, and bridges engineering, urban engineering and regional development, and project management.

All students used the platform Microsoft Teams for online classes.

\subsection{Method}

This research is a mix of a quantitative and qualitative studies. The qualitative study is based on the analysis of opinions. The answers have been analyzed to extract keywords then grouped on categories and topics. A number of 44 students mentioned one disadvantage, 41 students mentioned two, 64 mentioned three and the rest of 28 students mentioned four disadvantages or more. Overall, a total of 322 disadvantages of online classes have been identified.

To better understand the relationship between stress, frustration, and boredom, a quantitative analysis was done. The variables used in this respect and the descriptive statistics (mean and standard deviation) are presented in Table 1 .

Table 1. Descriptive statistics $(\mathrm{N}=177)$

\begin{tabular}{|l|l|c|c|}
\hline Item & Statement & $\mathrm{M}$ & $\mathrm{SD}$ \\
\hline FE & Online lectures are a frustrating experience & 3.18 & 1.43 \\
\hline SE & Online lectures are a stressful experience & 3.02 & 1.47 \\
\hline B & Online lectures make learning more boring & 3.12 & 1.47 \\
\hline C & During online lectures, my concentration suffers & 3.59 & 1.49 \\
\hline D & Online lectures make learning more difficult & 3.28 & 1.40 \\
\hline F & After online lectures, I feel more tired & 3.55 & 1.48 \\
\hline
\end{tabular}


The mean value of all variables is over the neutral value suggesting a moderate feeling of frustration, stress, boredom, and fatigue. The highest mean values are related to concentration and learning difficulties during the online lectures and feeling tired after the online lectures.

\section{Results}

\subsection{Analysis of quantitative data}

First, the correlation between variables has been examined using the Pearson correlation coefficient. The correlation is presented in Table 2.

As it could be noticed, the correlation coefficients range between 0.55 and 0.76 , showing a moderate to good correlation. The highest correlation is between stress and fatigue, boredom and frustration, learning difficulties and frustration, and boredom and learning difficulties.

Table 2. Correlation between variables $(\mathrm{N}=177)$

\begin{tabular}{|l|c|c|c|c|c|c|}
\hline & FE & SE & B & C & D & F \\
\hline FE & 1 & & & & & \\
\hline SE & 0.74 & 1 & & & & \\
\hline B & 0.75 & 0.59 & 1 & & & \\
\hline C & 0.59 & 0.63 & 0.59 & 1 & & \\
\hline D & 0.74 & 0.66 & 0.72 & 0.55 & 1 & \\
\hline F & 0.63 & 0.76 & 0.60 & 0.64 & 0.58 & 1 \\
\hline
\end{tabular}

Based on the analysis of qualitative data and the evidence from literature, boredom, concentration difficulties, and learning difficulties have been used as variables predicting a frustrating learning experience.

Table 3. Regression analysis results for frustrating experience $(\mathrm{N}=177)$

\begin{tabular}{|l|r|r|r|r|}
\hline Variable & Coefficient & Standard err & t-value & $\mathrm{p}$-value \\
\hline Intercept & 0.194 & 0.182 & 1.063 & 0.289 \\
\hline $\mathrm{B}$ & 0.389 & 0.065 & 5.948 & 0.000 \\
\hline $\mathrm{C}$ & 0.145 & 0.054 & 2.681 & 0.008 \\
\hline $\mathrm{D}$ & 0.380 & 0.067 & 5.676 & 0.000 \\
\hline $\mathrm{R}^{2}=0.664$, Adjusted $\mathrm{R}^{2}=0.658, \mathrm{~F}(4,172)=114.098, \mathrm{p}<0.001$ \\
\hline
\end{tabular}

Table 3 presents the standardized regression coefficients $(\beta)$ and their significance. Multiple correlation $(\mathrm{R}=0.815)$ for regression was significantly 
different from zero: $F(3,173)=114.098, p=0.000$. The adjusted $R^{2}$ value indicates that $65.84 \%$ of the variability in $\mathrm{FE}$ is predicted by the independent variables.

All predictors are significant at $\mathrm{p}<0.01$ level. The most important factors are boredom $(\beta=0.3589, p=0.000)$ and learning difficulties $(\beta=0.380$, $\mathrm{p}=0.000)$.

\subsection{Analysis of qualitative data}

\subsubsection{Overview}

Based on the answers of students, a total of 322 disadvantages of the online classes have been identified that are synthesized in Table 4 .

A total of 5 topics have been identified: general issues, technical issues, learning difficulties, lack of face-to-face (physical) interaction, and motivation. The opinions related to the four variables analyzed in this study have been grouped under the topic "general".

\begin{tabular}{|c|c|c|}
\hline Category / Advantage & No & $\%$ \\
\hline General & 44 & 13.66 \\
\hline Fatigue & 21 & \\
\hline Stress & 11 & \\
\hline Boredom & 8 & \\
\hline Frustration & 4 & \\
\hline Technical issues (Internet) & 34 & 10.56 \\
\hline Learning difficulties & 125 & 38.82 \\
\hline Concentration (attention) & 48 & \\
\hline Laboratory works (hands-on) & 31 & \\
\hline Understanding & 30 & \\
\hline Teachers' skills & 14 & \\
\hline Workload & 9 & \\
\hline Lack of face-to-face interaction & 99 & 30.75 \\
\hline Student-teacher interaction & 47 & \\
\hline Student-student interaction & 30 & \\
\hline Communication issues & 12 & \\
\hline Socialization issues & 10 & \\
\hline Motivation and engagement & 15 & 4.66 \\
\hline Low motivation & 8 & \\
\hline Low implication & 7 & \\
\hline Other & 5 & 1.55 \\
\hline Total & 322 & 100.00 \\
\hline
\end{tabular}


The main disadvantages of online classes are the learning difficulties, including concentration issues and the lack of physical interaction that is reflected in communication, socialization, interaction with the teachers, and interaction with colleagues.

\subsubsection{Frustration, stress, boredom, and fatigue}

The most frequent general issue mentioned by students was fatigue $(6.52 \%)$. Students related fatigue with prolonged exposure to the computer screen and complained about discomfort for the eyes ("permanent fatigue due to continuos looking at the screen", "is more tiring since is difficult to stay several hours in front of the screen", "problems with the eyes", "I have head, eyes, and back pains"). Stress was mainly related to technical issues and the fear to lose the internet connection.

Boredom has been related to the loss of attention, concentration, and motivation ("students are connected but they are doing something else since the presentation is boring", "the online class is boring if students get not involved").

Many students mentioned several of these aspects ("stressing, tiring, boring you can't learn well", "boredom, fatigue", "increased stress, fatigue", "increased stress, problems with the eyes", "very tiring, tiring for the eyes, tiring for the brain").

Frustration is a generally negative effect that has many causes. The shift to online lectures invaded the personal space ("I used to stay at the computer in my free time, to play and talk with friends... now I have to stay more in front of the computer doing something quite different than before, which became frustrating because my only corner of happiness has been taken").

Another important source of frustration is the lack of face-to-face communication ("we don't know ou group colleagues, the brakes between courses and seminar don't make sense").

\subsubsection{Learning difficulties}

Most learning issues mentioned by students refer to concentration difficulties $(14.91 \%)$, understanding difficulties $(9.32 \%)$, lack of laboratory works (6.52\%), and teachers' skills (4.35\%).

Most of the students mentioned that learning is more difficult since 
attention and concentration are lower than in traditional classes. Many of them pointed to the lack of communication and interaction with the teacher and their colleagues. Nine students (out of 30) mentioning difficulties in understanding online courses, seminars and laboratories also mentioned the loss of attention.

\section{Attention and concentration issues}

Most students complained about the loss of attention during online lectures, for various reasons ("I lose attention very quickly", "the concentration is not the same", "you are not 100\% focused", "when you are bored you no longer pay attention", "during online classes you can do something else and the attention is lower").

\section{Understanding difficulties}

Students mentioned that courses and seminars are more difficult to understand than in traditional classes ("seminars are more difficult to understand since the attention is lower", "I don't understand online lectures, ..., teachers don't understand that students don't understand", "it is hard to understand assignments", "it is difficult to understand from the start certain things", "especially practical works are more difficult to understand than in class", "you can't understand as in class").

They also related the understanding difficulties to the lack of physical interaction ("is more difficult to understand the information from the teacher", "some explanations are more difficult to understand than in face-toface classes") and with the loss of attention ( "we don't pay attention, we don't understand", "I can't concentrate, I don't understand almost anything, I can't communicate, I feel frustrated"),.

\section{Laboratory work}

Students complained about the loss of hands-on experience in the laboratory ("we can't understand laboratory works", "practice is a big disadvantage since we are not physically in the lab, we don't use the instruments", "online labs don't make sense", "we don't have the same motivation, we don't practice", "at practical disciplines is more difficult to understand").

\section{Other learning difficulties}

Other learning difficulties are related to the increased workload ("dense daily schedule") and teachers' skills ("more effort required by teachers since we are working from home", "some teachers don't provide explanations", "some 
teachers are not skilled for online teaching". "some teachers don't know to make the lectures attractive").

\subsubsection{Lack of interaction and communication}

Communication and interaction issues mentioned by students refer to the lack of student-teacher interaction (14.60\%), student-student interaction $(9.32 \%)$, communication (3.73\%), and socialization(3.11\%).

Interaction with the teacher

Several students related the lack of interaction with the teacher to the loss of attention ("the interaction between students and the teacher decreases and you could be easily distracted", "loss of attention, the low interaction with the teacher") and to the difficulties in understanding ("teachers can't understand that students don't understand", "students provide less feedback, the teacher doesn't notice the facial expression of the students", "interaction with the teacher and the presentation in the class").

Interaction with colleagues, communication, and socialization

Students related the lack of physical interaction to the teamwork (there is no teamwork, we don't know our colleagues", "I miss my colleagues, teamwork is more difficult", "lack of direct communication makes more difficult the laboratory works"), to the students' community "lack of collectivity, lack of interaction").

They also related these issues to learning ("the class provides a social environment; students connect to online lectures but they are not present", "the transfer of information is more difficult without face-to-face interaction").

\subsubsection{Other negative aspects}

Other issues mentioned by students refer to an internet connection (10.56\%), motivation (2.48\%), and engagement $(2.17 \%)$.

\section{Internet connection}

The internet connection has been mentioned as the main technical issue. For many students, this was an important stressor ("fear of losing connection during exams", "once the internet is down, is difficult if not impossible to connect to the online lecture", "if the internet doesn't work you lose lectures", 
"sometimes the connection is poor and you miss part of the lesson").

\section{Low motivation and engagement}

Students related the lack of motivation by understanding issues ("you don't understand, you lose the desire to attend lectures"), interaction issues ("the atmosphere which makes you interested", "lack of interaction, the interest to learn disappears"), and lack of practice ("it had been nice to participate physically to the lab and to get involved ourselves in experiments", "we are no longer motivated to learn, we can't practice").

\subsection{Discussion}

The students' opinions show that distance learning during the pandemic is a frustrating and stressful experience. While the analysis of quantitative data revealed a significant and relatively high correlation between stress, frustration, boredom, and fatigue, the qualitative analysis shed light on the relationship between these variables and as well as on the relationships with other shortcomings of distance education.

Students are frustrated for many reasons. The regression analysis revealed three predictors: boredom, concentration, and learning difficulties. The analysis of qualitative data highlighted other important reasons: lack of faceto-face communication and socialization, lack of interaction with the teacher, lack of interaction with colleagues, and lack of hands-on experience. The results are similar to the findings of Hagedorn et al. (2021) who found both academic and psychosocial sources of frustration.

For construction engineering students, the laboratory activities have particular importance for the future profession and represent a typical arena for social learning: students work in teams, learn by doing, are directly involved in experiments, learn by interacting with the teacher and their colleagues. The limitation of practical activities is not only a source of frustration but also a source of understanding issues and learning difficulties. The results of this study are in line with similar findings of Asgari et al. (2021) and Johnson \& Barr (2021).

Learning difficulties were an item rated over the neutral value, less than fatigue (3.55) and concentration difficulties (3.59), but more than boredom, stress, and frustration. The qualitative analysis revealed the learning difficulties were the main category, accounting for $38.84 \%$ from the total. Learning is more difficult, for many reasons: concentration and 
understanding difficulties, low level of motivation and engagement, lack of practical activities (laboratory works), boring lectures, and increased workload. The results are in line with many similar findings from the literature (Aguilera-Hermida, 2020; Hagedorn et al., 2021; Lamanauskas \& Makaraskaite-Petkevitciene, 2021; Wang et al., 2021). The negative opinions as regards the quality of lectures and explanations are raising attention to an important factor that is influences the students' acceptance of distance learning: teachers' self-efficacy (Santi et al., 2020).

Lack of face-to-face interaction was the second category of shortcomings mentioned by students $(30.75 \%)$. The qualitative analysis revealed that communication and interaction is not only social need but also a key ingredient for a better understanding and learning. First o all, as several students noticed, in face-to-face classes, the teacher can see the facial expressions of students and thus realize the degree to which they understand. Second, if they don't understand, students may ask the teacher additional explanations, which may be very often during seminars and laboratories. Last but not least, students learn by interacting with each other during practical activities.

The analysis of students' opinions revealed the frustration of changing the meaning of home by the shift to an exclusive online education. As Gezici Yalçın, \& Düzen (2021) shown, during the pandemic the boundaries of home expanded towards inside by assuming more functions and meanings than ever.

Last but not least, as Rahiem (2020) noticed, online education during the pandemic is paradoxical in that advantages are mixed with disadvantages and the balance may be quite different for different categories of students. A recent study carried on at the same university of construction engineering revealed several benefits of online learning (Manea et al., 2021). While the advantages in terms of comfort and time flexibility have been beneficial for many students, other advantages in terms of money savings were mentioned by students residents in other localities. This explains why 40 students out of 217 didn't mentioned any disadvantage.

There are several limitations of this work. First, the sample is relatively small and the students are from only one university. Second, the analysis of frustration and stress is mainly related to the learning process. Other factors that create these feelings, such as isolation or fear of not getting infected have not been taken into consideration. 


\section{Conclusion}

The restrictions during the pandemic forced universities to migrate from traditional to exclusive online classes. As existing research shows, this shift to distance learning has a differential impact depending on many factors. In this paper, the disadvantages of distance learning as perceived by students from a construction engineering university have bee analyzed.

The analysis students' perceptions revealed a significant correlation between stress, frustration, boredom, and fatigue. These negative aspects are mainly related to the prolonged exposure to the computer screen, issues within Internet connection, concentration and understanding difficulties, lack of interaction with teachers and colleagues, and lack of hands-on experience. The results should challenge universities and teachers to find solutions for better crisis response and future improvements of the educational system.

\section{References}

Aguilera-Hermida, A. P. (2020). College students' use and acceptance of emergency online learning due to COVID-19. International Journal of Educational Research Open, 1, 100011.doi:10.1016/j.ijedro.2020.100011.

Aristovnik, A., Keržič, D., Ravšelj, D., Tomaževič, N., \& Umek, L. (2020). Impacts of the COVID-19 pandemic on the life of higher education students: A global perspective. Sustainability, 12(20), 8438. Doi: 10.3390/su12208438.

Asgari S, Trajkovic J, Rahmani M, Zhang W, Lo RC, Sciortino A (2021) An observational study of engineering online education during the COVID-19 pandemic. PLOS ONE 16(4): e0250041, DOI:10.1371/journal.pone.0250041

Chakraborty, P., Mittal, P., Gupta, M. S., Yadav, S., \& Arora, A. (2020). Opinion of students on online education during the COVID-19 pandemic. Human Behavior and Emerging Technologies, 357-365, DOI: 10.1002/hbe2.240.

Day, T., Chang, I. C. C., Chung, C. K. L., Doolittle, W. E., Housel, J., \& McDaniel, P. N. (2021). The immediate impact of COVID-19 on postsecondary teaching and learning. The Professional Geographer, 73(1), 1-13. DOI:

10.1080/00330124.2020.1823864Debowska A, Horeczy B, Boduszek D, Dolinski D (2020). A repeated cross-sectional survey assessing university students' stress, depression, anxiety, and suicidality in the early stages of the COVID-19 pandemic in Poland. Psychological Medicine, 1-4. doi:10.1017/S003329172000392X

Deci, E. L., and Ryan, R. M. (2008). Self-determination theory: A macro theory of human motivation, development, and health. Canadian Psychology 49, 182-185. DOI: 10.1037/a0012801

Faize, F. A., \& Nawaz, M. (2020). Evaluation and Improvement of students' satisfaction in 
online learning during COVID-19. Open Praxis, 12(4), 495-507. DOI:10.5944/openpraxis. 12.4.1153

Furlonger, B., \& Gencic, E. (2014). Comparing satisfaction, life-stress, coping, and academic performance of counseling students in on-campus and distance education learning environments. Australian Journal of Guidance and Counselling, 24(01), 76-89. https://doi.org/10.1017/jgc.2014.2

Gaikwad, H. V., \& Kulkarni, S. S. (2021). Unmasking Students' Learning Experiences during Coronavirus Pandemic. Journal of Engineering Education Transformations, 34, 219-225.

Gorghiu G, Lamanauskas V, Makarskaite-Petkeviciene R, Manea IV, Pribeanu C (2021) Frustration and stress in the online education of university students from Lithuania and Romania. Proceedings of ELSE 2021 Conference, Bucharest 22-23 April

Gezici Yalçın, M., Düzen, N.E. (2021) Altered Meanings of Home Before and During COVID-19 Pandemic. Hu Arenas. https://doi.org/10.1007/s42087-021-00185-3

Hagedorn, R.L., Wattick, R.A. \& Olfert, M.D. (2021) "My Entire World Stopped": College Students' Psychosocial and Academic Frustrations during the COVID-19 Pandemic. Applied Research Quality Life. https://doi.org/10.1007/s11482-021-09948-0

Johnson, J.E. \& Barr, N.B. (2021) Moving hands-on mechanical engineering experiences online: Course redesigns and student perspectives. Online Learning, 25(1), 209-219. doi:10.24059/olj.v25i1.2465

Lamanauskas V, Makaraskaite-Petkevitciene R (2021) Distance lectures in university studies: advantages, disadvantages, improvement. Contemporary Educational Technology, 13(3), ep. 309, DOI:10.30935/cedtech/10887.

Lautenbach, G., \& Randell, N. (2020). Through the Covid-19 looking glass: Coping skills for STEM educators in the time of a pandemic and beyond. Journal of Baltic Science Education, 19(6A), 1068-1077. doi:10.33225/jbse/20.19.1068

Manea, I.V., Macavei, T., \& Pribeanu, C. (2021). Perceived benefits of online lectures during the pandemic: a case study in engineering education. Pro Edu International Journal of Educational Sciences, 3(1), 35-41, DOI: 10.26520/peijes.2021.4.5.65-41

Mark, G., Gudith, D., \& Klocke, U. (2008. The cost of interrupted work: more speed and stress. In Proceedings of the SIGCHI Conference on Human Factors in Computing Systems, 107-110.

Mheidly, N., Fares, M. Y., \& Fares, J. (2020). Coping with stress and burnout associated with telecommunication and online learning. Frontiers in Public Health, 8, 672. DOI:10.3389/fpubh.2020.574969

Moawad, R. A. (2020). Online learning during the COVID-19 pandemic and academic stress in university students. Revista Românească pentru Educaţie Multidimensională, 12(1 Sup2), 100-107. DOI:10.18662/rrem/12.1sup1/252

Rahiem, M. D. (2020). The emergency remote learning experience of university students in Indonesia amidst the COVID-19 crisis. International Journal of Learning, Teaching and Educational Research, 19(6), 1-26. DOI: 10.26803/ijlter.19.6.1 
Santi, E.A., Gorghiu, G., \& Pribeanu, C. (2020). Teachers’ Perceived Self-Efficacy for Mobile Teaching and Learning. Revista Romaneasca pentru Educatie Multidimensionala, 12(1Sup2), 157-166. https://doi.org/10.18662/rrem/12.1sup1/259

Unger, S., \& Meiran, W. R. (2020). Student attitudes towards online education during the COVID-19 viral outbreak of 2020: Distance learning in a time of social distance. International Journal of Technology in Education and Science (IJTES), 4(4), 256-266.

Wang, X., Zhang, R., Wang, Z., \& Li, T. (2021). How Does Digital Competence Preserve University Students' Psychological Well-Being During the Pandemic? An Investigation from Self-Determined Theory. Frontiers in Psychology, 12, 1252. DOI:10.3389/fpsyg.2021.652594

Zurlo MC, Cattaneo Della Volta MF and Vallone F (2020) COVID-19 Student Stress Questionnaire: Development and Validation of a Questionnaire to Evaluate Students' Stressors Related to the Coronavirus Pandemic Lockdown. Frontiers in Psychology. 11:576758. DOI: 10.3389/fpsyg.2020.576758. 